\title{
Standard care quality determines treatment outcomes in control groups of HAART-adherence intervention studies: Implications for the interpretation and comparison of intervention effects.
}

Citation for published version (APA):

de Bruin, M., Viechtbauer, W., Hospers, H. J., Schaalma, H. P., \& Kok, G. J. (2009). Standard care quality determines treatment outcomes in control groups of HAART-adherence intervention studies: Implications for the interpretation and comparison of intervention effects. Health Psychology, 28, 668-674.

https://doi.org/10.1037/a0015989

Document status and date:

Published: 01/01/2009

DOI:

10.1037/a0015989

Document Version:

Publisher's PDF, also known as Version of record

Document license:

Taverne

Please check the document version of this publication:

- A submitted manuscript is the version of the article upon submission and before peer-review. There can be important differences between the submitted version and the official published version of record. People interested in the research are advised to contact the author for the final version of the publication, or visit the DOI to the publisher's website.

- The final author version and the galley proof are versions of the publication after peer review.

- The final published version features the final layout of the paper including the volume, issue and page numbers.

Link to publication

\footnotetext{
General rights rights.

- You may freely distribute the URL identifying the publication in the public portal. please follow below link for the End User Agreement:

www.umlib.nl/taverne-license

Take down policy

If you believe that this document breaches copyright please contact us at:

repository@maastrichtuniversity.nl

providing details and we will investigate your claim.
}

Copyright and moral rights for the publications made accessible in the public portal are retained by the authors and/or other copyright owners and it is a condition of accessing publications that users recognise and abide by the legal requirements associated with these

- Users may download and print one copy of any publication from the public portal for the purpose of private study or research.

- You may not further distribute the material or use it for any profit-making activity or commercial gain

If the publication is distributed under the terms of Article 25fa of the Dutch Copyright Act, indicated by the "Taverne" license above,

Download date: 26 Apr. 2023 


\title{
Standard Care Quality Determines Treatment Outcomes in Control Groups of HAART-Adherence Intervention Studies: Implications for the Interpretation and Comparison of Intervention Effects
}

\author{
Marijn de Bruin \\ Maastricht University and Wageningen University
}

\author{
Wolfgang Viechtbauer, Harm J. Hospers, \\ Herman P. Schaalma, and Gerjo Kok \\ Maastricht University
}

\begin{abstract}
Objective: Clinical trials of behavioral interventions seek to enhance evidence-based health care. However, in case the quality of standard care provided to control conditions varies between studies and affects outcomes, intervention effects cannot be directly interpreted or compared. The objective of the present study was to examine whether standard care quality (SCQ) could be reliably assessed, varies between studies of highly active antiretroviral HIV-adherence interventions, and is related to the proportion of patients achieving an undetectable viral load ("success rate"). Design: Databases were searched for relevant articles. Authors of selected studies retrospectively completed a checklist with standard care activities, which were coded to compute SCQ scores. The relationship between SCQ and the success rates was examined using metaregression. Main Outcome Measures: Cronbach's alpha, variability in SCQ, and relation between SCQ and success rate. Results: Reliability of the SCQ instrument was high (Cronbach's alpha $=.91)$. SCQ scores ranged from 3.7 to 27.8 (total range $=0-30)$ and were highly predictive of success rate $(p=.002)$. Conclusions: Variation in SCQ provided to control groups may substantially influence effect sizes of behavior change interventions. Future trials should therefore assess and report SCQ, and meta-analyses should control for variability in SCQ, thereby producing more accurate estimates of the effectiveness of behavior change interventions.
\end{abstract}

Keywords: HIV, adherence, intervention, control group, meta-analysis

Supplemental materials: http://dx.doi.org/10.1037/a0015989.supp

Given that nonadherence to medical advice is a common problem, behavioral interventions can make an important contribution to evidence-based health care. Numerous studies have been conducted to test the effectiveness of interventions to improve adherence to medical treatments (Haynes et al., 2005; Ismail, Winkley, \& Rabe-Hesketh, 2004; McDonald, Garg, \& Haynes, 2002; Simoni, Pearson, Pantalone, Marks, \& Crepaz, 2006). Systematic reviews and meta-analyses of these studies should allow health care professionals to make rational

Marijn de Bruin, Department of Work and Social Psychology, Maastricht University, Maastricht, the Netherlands; Department of Communication Science, Wageningen University, Wageningen, the Netherlands; Wolfgang Viechtbauer, Department of Methodology and Statistics, Maastricht University, Maastricht, the Netherlands; Harm J. Hospers, Herman P. Schaalma, and Gerjo Kok, Department of Work and Social Psychology, Maastricht University, Maastricht, the Netherlands.

We thank Charles Abraham (University of Sussex) and Susan Michie (University College London) for sharing their Coding Manual to Identify Behavior Change Techniques in Behavior Change Intervention Descriptions (2007; available from the authors), and Charles Abraham, Susan Michie, and Dolores Albarracin (University of Illinois) for fruitful discussions and feedback on drafts of this article. We would also like to express our gratitude to all authors who made this project possible by cooperating with our requests for additional study data and information.

Correspondence concerning this article should be addressed to Marijn de Bruin, PO Box 8130, 6700 EW Wageningen, the Netherlands. E-mail: marijn.debruin@wur.nl decisions about evidence-based care using the entirety of available evidence (Higgins \& Green, 2005). However, whereas intervention characteristics are usually described and analyzed in detail in research trials and meta-analyses, the quality of care provided to control conditions receives considerably less attention (i.e., what is normally described as standard or usual care. In this article, we refer to it as standard care). Yet, as Wagner and Kanouse (2003) have argued, standard care activities may affect adherence behaviors and thus clinical outcomes. In addition, standard care practices may vary between different sites, implying that the assessment and reporting of standard care are essential for the interpretation and comparison of intervention effects. To investigate this alarming idea, we focused on studies that evaluated the effectiveness of interventions to improve adherence to highly active antiretroviral therapy (HAART). Our aim was to develop a tool to reliably assess standard care quality (SCQ), determine whether SCQ varied between studies, and examine whether SCQ was related to the proportion of patients achieving undetectable viral loads ("success rate") while receiving standard care only.

Theory- and evidence-based behavior change interventions to promote health behaviors consist of a set of techniques (e.g., education, feedback, goal setting) intended to change specific determinants of behaviors (e.g., education to increase knowledge, feedback to raise awareness, goal setting to enhance self-efficacy). The determinants targeted by a systematically developed intervention are those that have been identified as most important for the target behaviors. Both identifying the important determinants and selecting corresponding 
behavior change techniques are based on behavioral theory and scientific evidence. Theoretically, the adequate application of relevant behavior change techniques in practical intervention activities should alter the most important behavioral determinants, which in turn should change behaviors, ultimately leading to improved health and quality of life of those targeted by the intervention (Bartholomew, Parcel, Kok, \& Gottlieb, 2006). On the basis of this framework, the quality of an intervention can be defined as the degree to which effective behavior change techniques are adequately applied to important determinants of target behaviors.

Once a behavior change intervention has been developed, its efficacy is usually investigated in a trial comparing an intervention condition with a control condition. In general, the control condition is, just as the intervention condition, exposed to behavior change techniques. For example, standard clinical care may encompass techniques such as education to increase knowledge about the disease and treatment, persuasive communication about the benefits of adherence, or planning coping responses to deal with anticipated problems. Just as in the intervention group, these techniques have the potential to alter important determinants and consequently behavior and health. Therefore, testing the effectiveness of a behavior change intervention in a clinical trial is actually a test of the hypothesized superior quality of one intervention (i.e., intervention care) over another (i.e., standard care). Because the potential superiority of intervention care depends on the opportunity to alter important determinants of behavior that have not been (adequately) addressed by standard care, the quality level of standard care determines to a large extent how much improvement in determinants, behavior, and health can be achieved with a behavior change intervention.

In meta-analyses of behavior change interventions, study outcomes are first converted into a common effect size measure, which enables comparison of study effects. If SCQ affects health behavior and consequently clinical outcomes, the effect size produced by a similar intervention in settings with different SCQ will be different (just as interventions of different quality tested against standard care with different quality can result in a similar effect size). Then, if the quality of standard care varies between studies, intervention effects cannot be interpreted without ample descriptions of the level of standard care against which these effects were achieved. In addition, meta-analyses not controlling for variability in SCQ may then under- or overestimate overall intervention quality and the effectiveness of intervention techniques.

\section{Study Objectives}

Our first aim was to use the theoretical framework for intervention quality, as described in the introduction, to develop a tool to assess SCQ. This assessment tool was then used to determine SCQ in studies that investigate the effectiveness of interventions to improve adherence to HAART. Finally, we examined whether SCQ was actually associated with clinical success rates among HIV-infected patients who receive standard care, and whether variations in SCQ explain clinically relevant differences in success rates between the studies.

\section{Method}

\section{Literature Search and Selection Procedure}

Embase, PsycINFO, and Medline were searched for articles describing HAART-adherence intervention trials published be- tween January 1996 and December 2006. The search included terms concerned the disease or treatment (HIV, AIDS, HAART, antiretroviral, ARV), the behavior ([non]adherence, [non]compliance, [non]persistence), and the intervention (interv*, improv*, promot*, increas*, enhanc*) in the title or abstract. In total, 4,603 records were examined (including 1,527 duplicates). The aim was to identify adherence intervention studies with a within- or between-subjects design. Target groups operating in a fundamentally different context, or who faced challenges that were essentially different from those of the main study sample, were excluded: intravenous drug users, age $<18$ years, studies conducted in developing countries, alcohol-dependent people, or people with psychiatric problems. In addition to this search, published reviews on HAART-adherence-improving interventions were examined to check for additional studies; however, no new articles were found. Of the examined records, 47 appeared to address intervention effectiveness trials related to HAART adherence and were examined in more detail. Two reviewers (authors MdB and $\mathrm{HJH}$ ) decided which of these were relevant. Eighteen studies were excluded because of methodological inferiority (historic control group, biased control condition), no intervention aimed at adherence, or directly observed therapy intervention (i.e., no intervention on autonomous behavior). This yielded a final sample of 29 studies that were included in the present review.

\section{Assessment of SCQ}

We developed a checklist presenting a wide range of practical adherence activities for the assessment of standard care (see Supplemental Materials). These activities were derived from descriptions of standard care activities in the 29 selected studies, combined with observations during participatory research in the HIV clinic of the Academic Medical Centre, Amsterdam. Next, this checklist was sent to the corresponding authors of the selected studies. These authors were asked whether or not activities had been "delivered systematically to all patients" in their standard care condition. Authors responded by checking "Yes," "No," or “?" (i.e., don't know) and were prompted to report additional standard adherence care activities that were not listed. Items in the standard care checklist that were answered with a question mark were recoded as "No."

To determine which standard care activities could be considered as behavior change techniques targeting important determinants of adherence behaviors, we developed a coding manual, including a taxonomy of behavior change techniques (available from the authors). This 41-item taxonomy is an adapted version of the 26-item taxonomy developed by Abraham and Michie (2008). All the techniques described in the adapted taxonomy are organized under the determinant they are supposed to affect. These determinants are derived from an integration of theoretical constructs from prevailing behavior (change) theories that have been found predictive of a range of different health behaviors (Bartholomew et al., 2006). Two coders, both social psychologists with extensive experience in developing theory- and evidence-based behavior change interventions (authors GK and HPS), were trained to use the taxonomy. The coders independently coded the complete range of standard care activities in the checklist (i.e., including the additional activities reported by individual authors) and discussed their findings. Differences in coding (i.e., three instances) were resolved through discussion. The coders identified a total of 27 
Table 1

The Standard Care Activities Coded That Were Coded as Applications of Effective Behavior Change Techniques, Grouped Under Important Determinants of Adherence Behavior

\begin{tabular}{|c|c|c|c|}
\hline Determinant & Standard care activity & Coded technique & Score \\
\hline \multirow[t]{3}{*}{ Knowledge } & Information about HIV, medication, and adherence & Provide general information & 1 \\
\hline & Use of illustrative materials to transfer information & Increase memory and understanding & 1 \\
\hline & Handing out brochure or written information & Additional channel: Brochure & 1 \\
\hline \multirow[t]{4}{*}{ Awareness } & Information about consequences of nonadherence & Risk communication & 1 \\
\hline & Encourage use of 7-day pill box & Direct feedback of behavior & 1 \\
\hline & Feedback of CD4 and viral load & Feedback of clinical outcome & 2 \\
\hline & Feedback of MEMS results ${ }^{\mathrm{a}}$ & Delayed feedback of behavior & 2 \\
\hline \multirow[t]{2}{*}{ Attitude } & Information about the importance of adherence & Persuasive communication & 1 \\
\hline & Encourage medication adherence & Persuasive communication & 1 \\
\hline \multirow[t]{4}{*}{ Self-efficacy } & Encourage storing spare doses in different places & Verbal persuasion & 1 \\
\hline & Plan ahead for holidays and weekends & Plan coping responses & 1 \\
\hline & Discuss general barriers and ways to overcome them & Plan coping responses & 1 \\
\hline & Determine cause of nonadherence and generate solutions & Plan coping responses & 2 \\
\hline \multirow[t]{4}{*}{ Intention } & Develop a medication intake schedule & Develop medication schedule & 1 \\
\hline & Tailor schedule to patients' lifestyle & Tailor medication schedule & 1 \\
\hline & Write down dosing schedule (time, medication, number of pills) & Medication schedule in writing & 1 \\
\hline & Encourage patients to organize social support & Use of social support & 1 \\
\hline \multirow[t]{2}{*}{ Action control } & Identify daily habits and plan intake at these times & Use of cues & 1 \\
\hline & Encourage use of alarm devices & Use of cues & 1 \\
\hline \multirow[t]{8}{*}{ Facilitation } & Provide information about side effects and how to deal with them & Cope with side effects & 1 \\
\hline & Social worker helps with housing, unemployment, legal issues & Reduce environmental barriers & 1 \\
\hline & Design new regimens when regimen is too complex & Individualize regimen & 1 \\
\hline & Follow-up telephone calls to inquire about difficulties & Continuous professional support & 1 \\
\hline & Delivery of medication at home & Provide materials & 2 \\
\hline & Patients with adherence problems return more frequently & Tailoring of number of visits & 2 \\
\hline & Told to contact health care professional in case of any problems & Continuous professional support & 2 \\
\hline & Inquire about side effects and take appropriate steps & Cope with side effects & 2 \\
\hline Maximum score & & & 34 \\
\hline
\end{tabular}

Note. Column 4 displays the number of points for each behavior change technique, that is, 1 if typically applied at the beginning of standard care, 2 if applied repeatedly over time (i.e., follow-up techniques).

${ }^{a}$ Electronic caps for pill bottles that register date and time of opening. Data can be downloaded and printed in reports.

techniques in the standard care checklist (see Table 1). This coding was then applied to code all individual checklists completed by the selected authors.

\section{Scoring Procedure for SCQ}

Because the techniques in the taxonomy were all considered effective and targeted important determinants of adherence, all techniques in the standard care checklist were assumed to contribute equally to the score of SCQ and received 1 point each. However, 7 of the 27 techniques concerned long-term activities that may recur during consecutive consultations. Therefore, these techniques were given 2 points. Note that 3 techniques comprise multiple standard care checklist items, which could result in partial scores (e.g., if 3 of 5 educational items in the standard care checklist were answered with "Yes," the score for the technique provide general information would be 0.6). The theoretical range of SCQ scores was $0-34$ points.

\section{Data Assessment for the Meta-Analysis}

Half the studies focused on HAART-experienced patients continuing their current treatment, the other half on patients starting a new treatment (new patients and patients switching treatment). The success rates for these two types of studies were determined as follows. To allow treatment-naïve patients commencing treatment to achieve an undetectable viral load, we collected the proportion of patients with an undetectable viral load in the control group after 6 months of standard care. Because treatment-experienced patients were already exposed to standard care at baseline, and for several practical and statistical reasons, ${ }^{1}$ we used baseline data from these studies.

SCQ was used as the main predictor in a mixed-effects metaregression model, using either the raw or the logit-transformed success rates as the outcome measure. Because the analyses for both outcome measures yielded essentially identical results, only the results for raw proportions are presented below. The amount of (residual) heterogeneity was estimated via restricted maximum likelihood. On the basis of methodological and theoretical considerations, we decided a priori to control for four potential moderators: (a) inclusion of patients continuing treatment versus patients

\footnotetext{
${ }^{1}$ We used baseline data from these studies because these patients received standard care prior to the baseline assessment. The baseline data therefore reflect the success rate under standard care conditions. The use of baseline data also allowed us to include all the participants in the analysis. Moreover, potential bias due to differential dropout across the studies could be avoided this way. Finally, it allowed standardization of the assessment time point. To control for the fact that we used baseline data for these studies and 6-month data for the other set of studies we included a dummy-coded moderator variable in the model.
} 


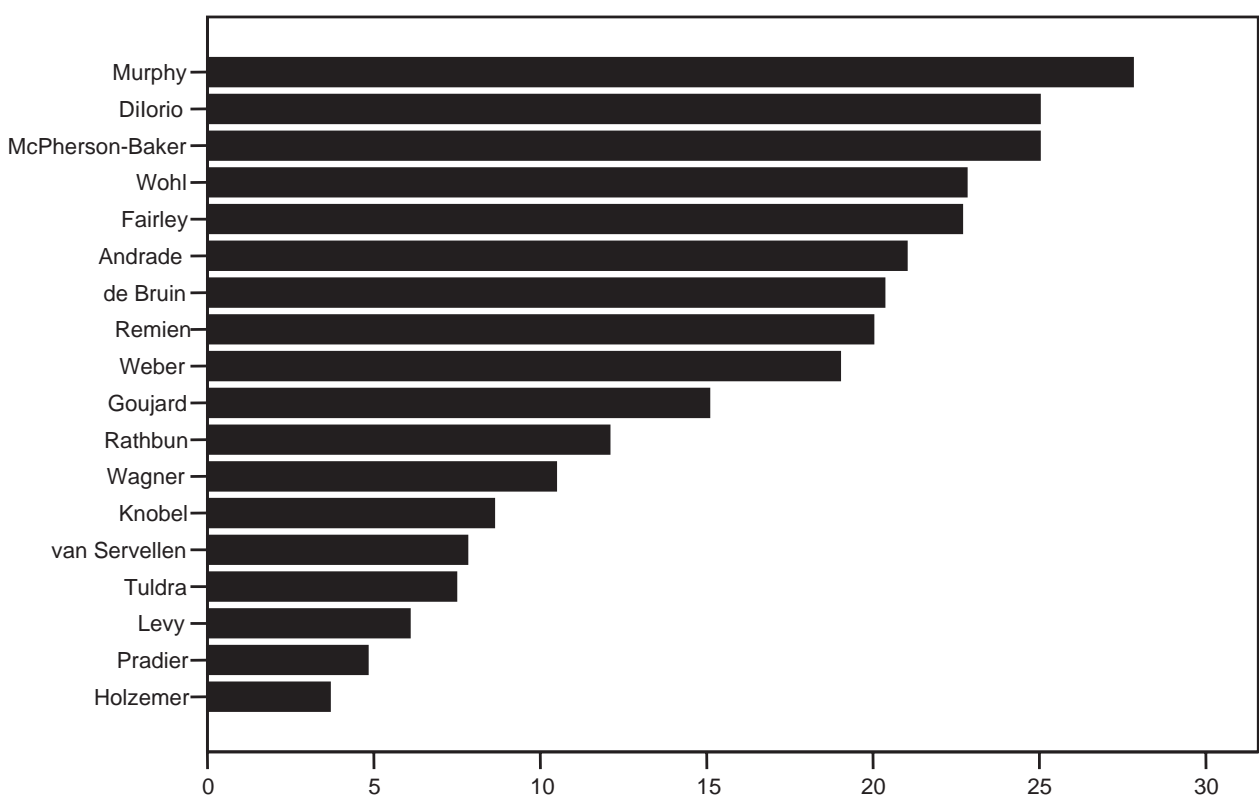

Figure 1. Variability in standard care quality.

starting (a new) treatment, (b) dominant ethnicity of the study sample (Caucasian vs. other; i.e., African American or Hispanic; Golin et al., 2002; Nellen et al., 2004), (c) baseline selection of patients with adherence problems versus no selection (Amico, Harman, \& Johnson, 2006), and (d) sensitivity of viral load assessments ( $<400$ vs. $\geq 400$ copies/ml). SCQ plus the other four moderators were simultaneously included in the metaregression model. We additionally examined (separately and in combination with the other moderators) whether the collection year of the viral load data was a relevant moderator (as regimen complexity has decreased over the years, and its efficacy has increased). Two coders (authors MdB and WV) independently examined the articles for success rate data and moderators. If the necessary data were not reported in an article, the authors were asked to provide these additional data.

\section{Results}

Of the 29 articles selected for this study, 27 authors responded to the request for completing the standard care checklist. The 2 remaining authors could not be contacted. Of the responding authors, 9 could not provide sufficient information about the standard care that was delivered to the patients in their study. The remaining authors responded by completing the standard care checklist, with only occasional missing data or "unknowns" $(M=$ $1.8, S D=2.0$, range $=0-5$ of 27 techniques).

Table 2

Study Details for the Meta-Analysis

\begin{tabular}{|c|c|c|c|c|c|c|c|}
\hline Author & Year & $\begin{array}{l}\text { Standard } \\
\text { care quality }\end{array}$ & $\begin{array}{c}n \\
\text { (undetectable/ dtectable) }\end{array}$ & $\begin{array}{l}\text { Dominant } \\
\text { ethnicity }\end{array}$ & $\begin{array}{l}\text { Patients' } \\
\text { treatment }\end{array}$ & $\begin{array}{l}\text { Selection on } \\
\text { nonadherence }\end{array}$ & $\begin{array}{l}\text { Viral load } \\
\text { sensitivity }\end{array}$ \\
\hline Andrade et al. & 2005 & 21.00 & $29(11 / 18)$ & Other & Starting & No & $<400$ \\
\hline Fairley et al. & 2003 & $22.67^{\mathrm{c}}$ & $33(24 / 9)$ & Caucasian & Continuing & Yes & $<400$ \\
\hline Goujard et al. & 2003 & 15.07 & $326(179 / 147)$ & Caucasian & Continuing & No & $<400$ \\
\hline Holzemer et al. & 2006 & 3.67 & $240(82 / 158)$ & Other & Continuing & No & 400 \\
\hline Knobel et al. & 1999 & 8.60 & $110(60 / 50)$ & Caucasian & Starting & No & $<400$ \\
\hline Murphy et al. & 2002 & 27.80 & $29(11 / 18)$ & Other & Continuing & Yes & 400 \\
\hline Pradier et al. & 2003 & 4.80 & $244(99 / 145)$ & Caucasian & Continuing & No & $<400$ \\
\hline Rathbun et al. & 2005 & 12.07 & $17(9 / 8)$ & Caucasian & Starting & No & $<400$ \\
\hline Remien et al. & 2005 & 20.00 & $215(88 / 127)$ & Other & Continuing & Yes & $<400$ \\
\hline Tuldra et al. & 2000 & 7.47 & $26(17 / 9)$ & Caucasian & Starting & No & 400 \\
\hline van Servellen & 2005 & 7.80 & $138(26 / 112)$ & Other & Continuing & Yes & 400 \\
\hline Wagner et al. & 2006 & 10.47 & $55(23 / 32)$ & Other & Starting & Yes & 400 \\
\hline Wohl et al. & 2006 & 22.80 & $54(40 / 14)$ & Other & Starting & No & 400 \\
\hline
\end{tabular}

${ }^{a}$ These are the final standard care quality scores after deleting the Follow-up Awareness 2 subscale. ${ }^{\mathrm{b}}$ Essentially identical outcomes were found when the percentages of Caucasian and non-Caucasian patients were included in the meta-regression model. ${ }^{\mathrm{c}}$ Noninteger scores (e.g., 0.8) can occur when a technique encompasses multiple standard care activities of which only some are delivered (e.g., 4/5). 
We computed the quality scores per study for each determinant in Table 1. For the three determinants that are also relevant for follow-up visits (the 2-point techniques under awareness, selfefficacy, and facilitation in Table 1), the follow-up scores were included separately. We computed Cronbach's alpha to check the internal consistency reliability of the SCQ instrument. When the mean scores of all subscales (i.e., determinants) were included, Cronbach's alpha was .895. Omitting the Follow-up Awareness subscale led to a relevant increase in Cronbach's alpha to .909. The high internal consistency is also expressed in the corrected itemtotal correlations between all subscales (range $r=.52-.90$, all $p s<.05$ ), except Follow-up Awareness $(r=.01, n s)$, with the total score. On the basis of these analyses, the Follow-up Awareness subscale was excluded from the final scale. The final scores ranged from 3.7 to 27.8 (total range $=0-30)$, with a mean of $15.5(S D=$ 8.0) and a median of 17.0 (see Figure 1).

Of the 18 studies, 14 measured and reported viral loads. However, 1 study selected only treatment-experienced patients with undetectable viral loads (100\% success), making it unsuitable for inclusion in the meta-analysis. Table 2 contains the data for the studies included in the meta-analysis. Data on the viral load status for a total of 1,516 patients were available from these 13 studies. The average proportion of patients with an undetectable viral load was estimated to be 0.48 (95\% confidence interval $[\mathrm{CI}]=0.39$, $0.57 ; p<.001)$ in an initial random effects model without moderators. However, the results were clearly heterogeneous $(Q=$ $135.51, d f=12, p<.001 ; I^{2}=92 \%$ ). Approximately $70 \%$ of the total amount of heterogeneity could be accounted for on the basis of SCQ and the other four moderators. The set of moderators as a whole was significant $(p<.001)$. Of the individual moderators, SCQ and ethnicity were significant $(p=.002$ and $p=.006$, respectively; all other $p s \geq .19$; removing the three nonsignificant moderators from the model did not alter the conclusions). Moreover, collection year of the viral load data was not a significant moderator when examined by itself or in combination with the other moderators ( $p=.66$ and $p=.29$, respectively).

Most notably, for a 1-point increase in SCQ, the proportion of patients with an undetectable viral load was estimated to increase on average by 0.014 points $(95 \% \mathrm{CI}=0.005,0.023)$. Therefore, a 15 -point difference in SCQ (the interquartile range for this variable) corresponds, on average, to a $21 \%$ difference in the proportion of patients with an undetectable viral load. Regardless of the SCQ, dominantly African American or Hispanic samples had on average a $23 \%(95 \% \mathrm{CI}=7 \%, 40 \%)$ lower chance of achieving virologic success than dominantly Caucasian samples. Figure 2 shows a scatterplot of SCQ against the observed proportions corrected for the influence of the other four moderators (the size of the points is proportional to their weight in the analysis). The solid line indicates the predicted average proportion as a function of SCQ and the dotted lines indicate the corresponding 95\% CI bounds.

\section{Discussion}

The purpose of this study was to investigate whether SCQ could be assessed in a reliable manner, whether it varied between studies, and whether these variations were related to clinically relevant differences in success rates among HIV-infected patients receiving HAART and standard care. The results indicate that the SCQ

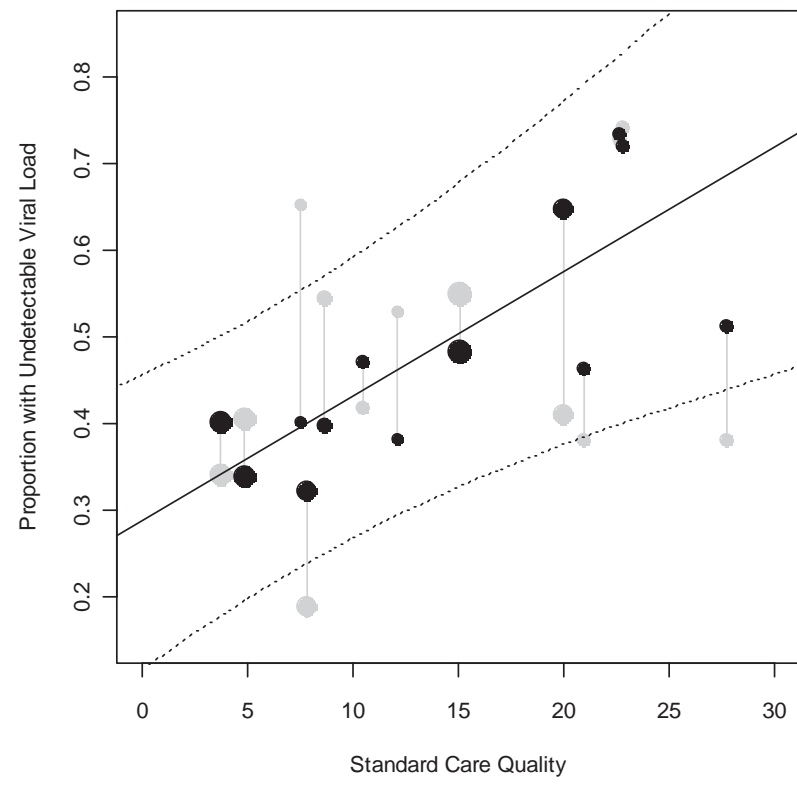

Figure 2. The proportion of participants with undetectable viral loads as a function of standard care quality. The figure displays the proportions before (gray dots) and after correction (black dots) for the influence of the other four moderators.

instrument is a reliable tool, and that SCQ varied considerably between reviewed studies. In addition, SCQ was significantly related to clinically relevant variations in treatment success rates: Patients' chances on an undetectable viral load depend to a large extent on the quality of standard care provided to them. These results suggest that not all patients in the Western world benefit fully from the available antiretroviral therapies, and that considerable increases in HAART (cost) effectiveness may be expected if standard care is optimized (Goldie et al., 2003). Moreover, these data indicate that variations in effect sizes (comparing intervention and standard care groups) between clinical trials may be substantially influenced by variations in the quality of standard care provided to control groups in these trials.

The findings suggest that future meta-analyses of HAARTadherence interventions need to assess and control for variability in SCQ so that more accurate estimates of intervention effectiveness can be produced. Furthermore, as Wagner and Kanouse (2003) also have argued, the substantial variation SCQ may well apply to behavior change interventions in fields other than adherence to HAART. For example, in a meta-analysis of randomized controlled trials of psychological interventions to improve glycemic control in patients with Type 2 diabetes, the authors reported sizable variations in standard care delivered to control patients: It ranged from 1 minimal education session by a nurse to 16 behavioral modification sessions by a multidisciplinary team (Ismail et al., 2004). This warrants meta-analyses of behavior change interventions in other fields to also assess and control for variability in SCQ delivered to their control groups so that more accurate estimates of intervention effectiveness can be achieved. In addition, systematic analyses of standard care in these fields can be useful to determine the effects and content of optimal standard care for treatments other than HAART. The instruments developed in this study may aid scholars in assessing SCQ in their domains. 
The results of the present study also highlight the usefulness of ample descriptions of SCQ in future publications of research trials. In the first place, this would enable those conducting meta-analyses to assess SCQ directly from published articles. In addition, health care professionals would be able to compare the quality of standard care in their clinic to that delivered to a control group, allowing wellinformed judgments about the probable effectiveness of an intervention in their clinic (Wagner \& Kanouse, 2003).

The results from the metaregression model indicate that ethnicity was also a significant predictor of clinical success. In particular, samples with non-Caucasians as the dominant ethnicity had, on average, a $23 \%$ lower chance of achieving full viral suppression than samples with Caucasians as the dominant ethnicity. Although the evidence regarding differences in clinical response between ethnicities is mixed, several authors have suggested that individual and environmental differences could lead to lower adherence rates among non-Caucasian patients and thus to a less successful treatment (Golin et al., 2002; Halkitis, Palamar, \& Mukherjee, 2008; Nellen et al., 2004). Regardless of the reasons for the present result, it is important to note that both SCQ and ethnicity are significant moderators when included simultaneously in the model. This suggests that the influence of these moderators is genuine and not attributable to some form of confounding between them (SCQ was on average actually slightly higher in studies with nonCaucasians as the dominant ethnicity).

There are several limitations to this study. In the first place, our assessment was limited to a sample of HAART-adherence intervention studies. Therefore, our findings cannot be generalized to other fields. Furthermore, although 27 of the 29 authors of the selected articles for this study responded to our request for information, 9 were not able to provide sufficient information on the standard care delivered in their study, and 5 other studies could not be included in the meta-analysis. In addition, the SCQ reports by the corresponding authors were retrospective, which could have resulted in less accurate responses. Finally, factors other than effective techniques to influence behavioral determinants may contribute to SCQ, such as the frequency and duration of contacts with health care professionals (Davidson et al., 2003).

The present research sought to develop useful instruments to assess the quality of standard care, to demonstrate that these instruments are sensitive to show variability in SCQ, and that these variations explain clinically relevant differences in clinical success rates in this domain. Future reviews and meta-analyses could investigate whether such variability is present in other domains, and, if so, include SCQ as a moderator in the analysis, thereby providing a more accurate understanding of the effectiveness of behavior change interventions and techniques to improve patients' health and well-being.

\section{References}

References marked with an asterisk indicate studies included in the meta-analysis.

Abraham, C., \& Michie, S. (2008). A taxonomy of behavior change techniques used in interventions. Health Psychology, 27, 379-387.

Amico, K. R., Harman, J. J., \& Johnson, B. T. (2006). Efficacy of antiretroviral therapy adherence interventions: A research synthesis of trials, 1996 to 2004. Journal of Acquired Immune Deficiency Syndromes, $41,285-297$.
*Andrade, S. A., McGruder, H. F., Wu, A. W., Celano, S. A., Skolasky, R. L., Selnes, O. A., et al. (2005). A programmable prompting device improves adherence to highly active antiretroviral therapy in HIVinfected subjects with memory impairment. Clinical Infectious Diseases, $41,875-882$.

Bartholomew, L. K., Parcel, G. S., Kok, G., \& Gottlieb, N. H. (2006) Planning health promotion programs: An intervention mapping approach. San Fransisco: Jossey-Bass.

Davidson, K. W., Goldstein, M., Kaplan, R. M., Kaufmann, P. G., Knatterud, G. L., Orleans, C. T., et al. (2003). Evidence-based behavioral medicine: What is it and how do we achieve it? Annals of Behavioral Medicine, 26, 161-171.

*de Bruin, M., Hospers, H. J., van den Borne, H. W., Kok, G., \& Prins, J. M. (2005). Theory- and evidence-based intervention to improve adherence to antiretroviral therapy among HIV-infected patients in the Netherlands: A pilot study. AIDS Patient Care and STDs, 19, 384-394.

*DiIorio, C., Resnicow, K., McDonell, M., Soet, J., McCarthy, F., \& Yeager, K. (2003). Using motivational interviewing to promote adherence to antiretroviral medications: A pilot study. Journal of the Association of Nurses in AIDS Care, 14, 52-65.

*Fairley, C. K., Levy, R., Rayner, C. R., Allardice, K., Costello, K., Thomas, C., et al. (2003). Randomized trial of an adherence programme for clients with HIV. International Journal of STD \& AIDS, 14, 805809.

Goldie, S. J., Paltiel, A. D., Weinstein, M. C., Losina, E., Seage, G. R., Kimmel, A. D., et al. (2003). Projecting the cost-effectiveness of adherence interventions in persons with human immunodeficiency virus infection. American Journal of Medicine, 115, 632-641.

Golin, C. E., Liu, H., Hays, R. D., Miller, R. D., Beck, C. K., Ickovics, J., et al. (2002). A prospective study of predictors of adherence to combination antiretroviral therapy. Journal of General Internal Medicine, 17, $756-765$.

*Goujard, C., Bernard, N., Sohier, N., Peyramond, D., Lançon, F., Chwalow, J., et al. (2003). Impact of a patient education program on adherence to HIV medication: A randomized clinical trial. Journal of Acquired Immune Deficiency Syndromes, 34, 191-194.

Halkitis, P., Palamar, J., \& Mukherjee, P. (2008). Analysis of HIV medication adherence in relation to person and treatment characteristics using hierarchical linear modeling. AIDS Patient Care and STDs, 22, 323-335.

Haynes, R. B., Yao, X., Degani, A., Kripalani, S., Garg, A., \& McDonald, H. P. (2005). Interventions for enhancing medication adherence. Cochrane Database of Systematic Reviews, 4. doi:10.1002/14651858 .CD000011.pub2

Higgins, J. P. T., \& Green, S. (2005). Introduction: Systematic reviews and the Cochrane Handbook. In J. P. T. Higgins \& S. Green (Eds.), Cochrane handbook for systematic reviews of interventions 4.2 .5 (pp. 15-17). Chichester, England: The Cochrane Library.

*Holzemer, W. L., Bakken, S., Portillo, C. J., Grimes, R., Welch, J., Wantland, D., et al. (2006). Testing a nurse-tailored HIV medication adherence intervention. Nursing Research, 55, 189-197.

Ismail, K., Winkley, K., \& Rabe-Hesketh, S. (2004). Systematic review and meta-analysis of randomized controlled trials of psychological interventions to improve glycaemic control in patients with Type 2 diabetes. Lancet, 363, 1589-1597.

*Knobel, H., Carmona, A., Lopez, J. L., Gimeno, J. L., Saballs, P., Gonzalez, A., et al. (1999). Adherencia al tratamiento antirretroviral de gran actividad: Impacto de una intervencion de asesoramiento individualizado [Adherence to highly active antiretroviral treatment: Impact of individualized assessment]. Enfermedades Infecciocas Microbiologica y Clinica, 17, 78-81.

*Levy, R. W., Rayner, C. R., Fairley, C. K., Kong, D. C. M., Mijch, A., Costello, K., et al. (2004). Multidisciplinary HIV adherence intervention: A randomized study. AIDS Patient Care and STDs, 18, 728-735. McDonald, H. P., Garg, A. X., \& Haynes, R. B. (2002). Interventions to 
enhance patient adherence to medication prescriptions. Journal of the American Medical Association, 288, 2868-2879.

*McPherson-Baker, S., Malow, R. M., Penedo, F., Jones, D. L., Schneiderman, \& N., Klimas, N. G. (2000). Enhancing adherence to combination antiretroviral therapy in non-adherent HIV-positive men. AIDS Care, 12, 399-404.

*Murphy, D. A., Lu, M. C., Martin, D., Hoffman, D., \& Marelich, W. D. (2002). Results of a pilot intervention trial to improve antiretroviral adherence among HIV-positive patients. Journal of the Association of Nurses in AIDS Care, 13, 57-69.

Nellen, J. F. J. B., Wit, F. W., de Wolf, F., Jurriaans, S., Lange, J. M., \& Prins, J. M. (2004). Virological and immunological response to HAART in indigenous and non-indigenous HIV-1 infected patients in the Netherlands: A cohort study. Journal of Acquired Immune Deficiency Syndromes, 36, 943-950.

*Pradier, C., Bentz, L., Spire, B., Tourette-Turgis, C., Morin, M., Souville, M., et al. (2003). Efficacy of an educational and counselling intervention on adherence to highly active antiretroviral therapy: French prospective controlled study. HIV Clinical Trials, 4, 121-131.

*Rathbun, R. C., Farmer, K. C., Stephens, J. R., \& Lockhart, S. M. (2005). Impact of an adherence clinic on behavioral outcomes and virologic response in the treatment of HIV infection: A prospective, randomized, controlled pilot study. Clinical Therapeutics, 27, 199-209.

*Remien, R. H., Stirratt, M. J., Dolezal, C., Dognin, J. S., Wagner, G. J., Carballo-Dieguez, A., et al. (2005). Couple-focused support to improve HIV medication adherence: A randomized controlled trial. AIDS, 19, 807-814.

Simoni, J. M., Pearson, C. R., Pantalone, D. W., Marks, G., \& Crepaz, N. (2006). Efficacy of interventions in improving highly active antiretro- viral therapy adherence and HIV-1 RNA viral load: A meta-analytic review of randomized controlled trials. Journal of Acquired Immune Deficiency Syndromes, 43, S23-S35.

*Tuldra, A., Fumaz, C. R., Ferrer, M. J., Bayes, R., Arnó, A., Balagué, M., et al. (2000). Two-arm controlled study to determine the efficacy of a specific intervention to improve long-term adherence to highly active antiretroviral therapy. Journal of Acquired Immune Deficiency Syndromes, 25, 221-228.

*Van Servellen, G., Nyamathi, A., Carpio, F., Pearce, D., Garcia-Teague, L., Herrera, G., et al. (2005). Effects of a treatment adherence enhancement program on health literacy, patient-provider relationships, and adherence to HAART among low-income HIV-positive Spanish speaking Latinos. AIDS Patient Care and STDs, 19, 745-759.

Wagner, G. J., \& Kanouse, D. E. (2003). Assessing usual care in clinical trials of adherence interventions for highly active antiretroviral therapy. Journal of Acquired Immune Deficiency Syndromes, 33, 276-277.

*Wagner, G. J., Kanouse, D. E., Golinelli, D., Miller, L. G., Daar, E. S., Witt, M. D., et al. (2006). Cognitive-behavioral intervention to enhance adherence to antiretroviral therapy: A randomized controlled trial. AIDS, 20, 1295-1302.

*Weber, R., Christen, L., Christen, S., Tschopp, S., Znoj, H., Schneider, C., et al. (2004). Effect of individual cognitive behavior intervention on adherence to antiretroviral therapy: Prospective randomized trial. Antiviral Therapy, 9, 85-95.

*Wohl, A. R., Garland, W. H., Valencia, R., Squires, K., Witt, M. D., Kovacs, A., et al. (2006). A randomized trial of directly administered antiretroviral therapy and adherence case management intervention. Clinical Infectious Diseases, 42, 1619-1627.

\title{
New Editor Appointed for Health Psychology, 2011-2016
}

Division 38 (Health Psychology) of the American Psychological Association is pleased to announce the appointment of a new editor for Health Psychology for a 6-year term beginning in 2011. As of July 1, 2010, all new manuscripts should be directed to:

\author{
Anne E. Kazak, PhD \\ The Children's Hospital of Philadelphia and \\ University of Pennsylvania \\ 34th and Civic Center Blvd. \\ Room 1486 CHOP North \\ Philadelphia, PA 19104-4399
}

Electronic manuscript submission: As of July 1, 2010, manuscripts should be submitted electronically to the new editor via the journal's Manuscript Submission Portal: http://www.apa.org/ journals/hea/submission.html

Manuscript submission patterns make the precise date of completion of the 2010 volumes uncertain. The current editor, Robert M. Kaplan, $\mathrm{PhD}$ will receive and consider new manuscripts through June 30, 2010. Should 2010 volumes be completed before that date, manuscripts will be redirected to the new editor for consideration in the 2011 volume. 